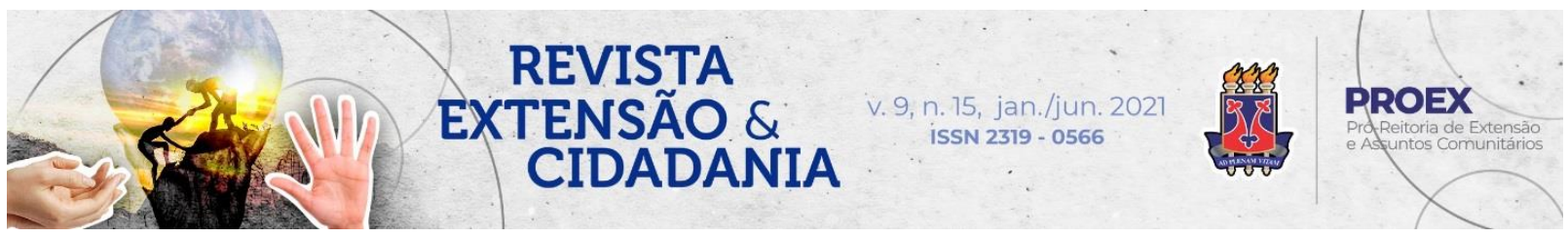

DOI: $10.22481 /$ recuesb.v9i15.8710

\title{
IMPLANTAÇÃO DA EXTENSÃO UNIVERSITÁRIA EM UM CURSO DE DIREITO EM ATENDIMENTO À RESOLUÇÃO CNE/CES Nº 7/2018
}

\section{Implementation of the university extension in a course of law in compliance with resolution cne/ces $7 / 2018$}

Alexandre Jacob ${ }^{1}$

\begin{abstract}
Resumo: Trata-se de relato de experiência da implantação de atividades de extensão universitária em um curso de Direito de uma faculdade no leste mineiro com o objetivo de tornar fática a Resolução CNE/CES nº. 7/2018, que prevê a obrigatoriedade para a extensão universitária em todos os cursos de graduação em 2021. Com fundamento na Lei de Diretrizes e Bases da Educação Nacional e no Projeto Pedagógico do Curso, as atividades de extensão visam integrar a Universidade à Comunidade. Durante a implantação no ano de 2020, fomos surpreendidos com a quarentena em razão da pandemia por Covid-19, o que poderia impactar negativamente nos objetivos, contudo, com a adoção de metodologias participativas foi possível obter resultados acima do esperado, com a adesão de quase todos os alunos do curso de Direito e uma pluralidade de atividades de extensão universitária desenvolvidas em meio a uma crise sanitária e econômica, o que leva à conclusão que a implantação da extensão universitária atende às determinações legais e aos seus objetivos de forma positiva e que as dificuldades impostas pela quarentena não foram suficientes para desanimar os alunos das ações relacionadas aos Direitos Humanos, essenciais, especialmente nesses períodos de crise.
\end{abstract}

Palavras-chave: Educação superior. Direito. Direitos humanos. Extensão universitária. Implantação positiva.

Abstract: This is an experience report of the implementation of university extension activities in a Law course at a college in eastern Minas Gerais with the aim of making Resolution CNE/CES 7/2018, which provides for mandatory university extension in all undergraduate courses in 2021. Based on the Law of Guidelines and Bases of National Education and the Pedagogical Project of the Course, the extension activities aim to integrate the University into the Community. During the implementation in 2020, we were surprised by the quarantine due to the pandemic by Covid-19, which could have a negative impact on the objectives, however, with the adoption of participatory methodologies it was possible to obtain results above expectations, with the adherence of almost all Law students and a plurality of university extension activities developed in the midst of a health and economic crisis, which leads to the

\footnotetext{
${ }^{1}$ Bacharel em Direito; Mestre em Ciências das Religiões. Professor da Faculdade Presidente Antônio Carlos de Aimorés, Minas Gerais, Brasil e da Faculdade de Ensino Superior de Linhares, Espírito Santo, Brasil. Orcid: https://orcid.org/0000-0002-8220-5418 E-mail: alexandre.jacob10@gmail.com
} 
conclusion that the implementation of university extension meets the legal requirements and its objectives in a positive way and that difficulties imposed by the quarantine were not enough to discourage students from actions related to Human Rights, which are essential, especially in these periods of crisis

Keywords: College education. Law. Human rights. University Extension. Positive deployment.

\section{Introdução}

As Atividades Acadêmicas de Extensão (AAE) no Curso de Direito da Faculdade Presidente Antônio Carlos de Aimorés, situada no Leste de Minas Gerais, aqui chamada Instituição de Ensino Superior (IES), tiveram início em 17 de fevereiro de 2020 com o primeiro contato com as turmas para explicação e orientações preliminares sobre a obrigatoriedade das atividades de extensão, a natureza da extensão universitária e as possibilidades de ações a serem desenvolvidas.

O fundamento legal está na Lei nº 9.394/1996, Lei de Diretrizes e Bases da Educação Nacional, que determina em seu artigo 43, incisos VI e VII, que a educação superior tem por finalidade:

VI - Estimular o conhecimento dos problemas do mundo presente, em particular os nacionais e regionais, prestar serviços especializados à comunidade e estabelecer com esta uma relação de reciprocidade;

$[\ldots]$

VII - Promover a extensão, aberta à participação da população, visando à difusão das conquistas e benefícios resultantes da criação cultural e da pesquisa científica e tecnológica geradas na instituição (BRASIL, 1996).

E, ainda, em seu artigo 44, inciso IV, esclarece que a educação superior abrangerá cursos de "extensão, abertos a candidatos que atendam aos requisitos estabelecidos em cada caso pelas instituições de ensino" (BRASIL, 1996).

Em se tratando de Extensão, o Conselho Nacional de Educação, por meio da Câmara de Educação Superior editou a Resolução $n^{\circ}$. 7, de 18 de dezembro de 2018, que estabelece diretrizes para atividades de extensão universitária, determinando em seu artigo $4^{\circ}$ que os cursos de graduação devem contemplar o mínimo de dez por cento do total da carga horária em programas e projetos de extensão, sob a forma de componente curricular. No artigo $7^{\circ}$ dispõe, ainda, que "são consideradas atividades de extensão as intervenções que envolvam diretamente as comunidades externas às instituições de ensino superior e que estejam vinculadas à formação

Revista Extensão \& Cidadania, v. 9, n. 15, p. 131-143 jan./jun. 2021. 
do estudante, nos termos desta resolução, e conforme normas institucionais próprias" (MEC, 2018).

Por sua vez, a IES editou, em 29 de janeiro de 2020, o Regulamento para Curricularização das Atividades de Extensão de seus cursos de graduação, integrando à matriz curricular dos cursos e, em especial ao curso de Direito, por meio do componente curricular Projeto Atividades Acadêmicas de Extensão no Curso de Direito (AAE), constituindo-se em um processo interdisciplinar, político-educacional, cultural, científico e tecnológico, visando à interação transformadora entre a Faculdade e a sociedade, por meio da produção e aplicação do conhecimento, em permanente articulação do ensino e da iniciação científica (UNIPAC, 2020).

As AAE no Curso de Direito desenvolvem-se na área temática Direitos Humanos. A área escolhida tem imediata identidade com o Curso de Direito e, portanto, oportuniza aos alunos tratar com propriedade do tema. Também é uma necessidade emergente deste século, posto que grandes avanços e grandes desafios foram e são ainda discutidos nesta dimensão, pois na medida em que a sociedade se desenvolve os conflitos sociais também a acompanham.

Outro aspecto relevante da escolha desta área temática está na aparente constatação que, malgrado a sociedade viva os direitos humanos, poucos cidadãos conseguem visualizá-los. Acerca dessa dificuldade, Flávia Piovesan esclarece:

Em face da indivisibilidade dos direitos humanos, há de ser definitivamente afastada a equivocada noção de que uma classe de direitos (a dos direitos civis e políticos) merece inteiro reconhecimento e respeito, enquanto outra classe de direitos (a dos direitos sociais, econômicos e culturais), ao revés, não merece qualquer observância. [...]. Sob esta ótica, está definitivamente superada a concepção de que os direitos sociais, econômicos e culturais não são direitos legais. São eles autênticos e verdadeiros direitos fundamentais, acionáveis, exigíveis e demandam séria e responsável observância. Por isso, devem ser reivindicados como direitos e não como caridade ou generosidade (PIOVESAN, 2016).

Como consequência, a sociedade em geral acaba sonegando os direitos que the pertencem. Esta carência, por si só, justifica a escolha de área tão imprescindível para emancipação da sociedade e formação cidadã dentro e fora dos muros escolares.

Neste diapasão, as AAE na área dos Direitos Humanos surgiram como hipótese mais viável em razão de os direitos humanos terem caráter coletivo e naturalmente intercultural, estando interligados a todas as dimensões e faculdades humanas, para nosso alunado e para o público alcançado pelas AAE seria muito mais gratificante fazê-los entender que o tema extrapola os espaços acadêmicos e jurídicos e está entre eles, onde estiverem.

Revista Extensão \& Cidadania, v. 9, n. 15, p. 131-143 jan./jun. 2021. 
Logo, concorda-se com Michel Jean Marie Thiollent e Maria Madalena Colette ao discutirem o melhor formato de atividade extensionista:

\begin{abstract}
Ao educando é preciso uma profunda reflexão sobre si próprio (autobiografia), sobre seu entorno e sobre as práticas sociais nas quais ele está engajado. Nesse contexto, a pesquisa-ação é vista como estratégia de autoformação. Estudantes e docentes atuam como membros ativos pertencentes a coletividades, instituições ou comunidades rurais ou urbanas, implicados em práticas sociais relacionadas com associações, cooperativas, sindicatos, grupos políticos ou de expressão cultural, dentre outros. (THIOLLENT; COLETTE, 2020, p. 61)
\end{abstract}

Nesse sentido, para Luiz Roberto Alves (2014), realizar atividades de extensão é ser educador comunicante, articular ensino, pesquisa e extensão, somando todos os elementos universitários e contribuições da comunidade, ressignificando o conhecimento.

\title{
As atividades acadêmicas de extensão no curso de Direito
}

A linha programática está relacionada aos Direitos de Grupos Sociais de forma imediata, abrangendo discussões acerca das questões de gênero, etnia e inclusão de grupos sociais e de forma mediata Atenção integral à mulher; Atenção integral à Criança; Atenção integral à terceira idade; Cooperação interinstitucional; Educação ambiental; Educação infantil; Empreendedorismo; Ensino médio; e Produção e difusão de material educativo.

A escolha da linha programática e seus desdobramentos foi ao encontro das demandas sociais levantadas pelos alunos durante os primeiros contatos para tratar da Extensão, sendo posteriormente incrementadas de acordo com o desenvolvimento das AAE.

De acordo com o artigo $4^{\circ}$ do Regulamento para Curricularização das Atividades de Extensão da IES, a Extensão configura-se nas modalidades de programas, projetos, cursos e oficinas, eventos e prestação de serviços (UNIPAC, 2020). O rol não é taxativo, posto que a finalidade maior está na integração com a sociedade, logo, as modalidades previstas não impedem o surgimento de outras novas, na medida em que as demandas surjam.

O Projeto de AAE desenvolve-se em três atividades extensionistas no curso de Direito: Cidadania nas Escolas, Cidadania em Ações e Solidariedade em Ações.

A atividade Cidadania nas Escolas busca promover a interação transformadora entre a IES e as Escolas de ensino infantil, fundamental, médio e técnico, públicas ou privadas, dos municípios atendidos por ela, por meio da produção e da aplicação do conhecimento, em permanente articulação do ensino e da iniciação científica, ancorada em processo pedagógico

Revista Extensão \& Cidadania, v. 9, n. 15, p. 131-143 jan./jun. 2021. 
único, voltado à disseminação do conhecimento em Direitos Humanos, tão necessário no tempo atual.

A atividade Cidadania em Ações busca promover a interação transformadora entre a IES e o setor público, o mercado, a sociedade civil organizada e o terceiro setor dos municípios atendidos por ela, pelo mesmo meio e processo, voltado à disseminação do conhecimento em Direito em cooperação interinstitucional.

Por sua vez, a atividade Solidariedade em Ações busca a mesma interação entre a IES e grupos sociais diversos, institucionalizados ou não-institucionalizados dos municípios atendidos por ela, voltado à disseminação do conhecimento em Direito de grupos sociais, na forma de campanhas de arrecadação, sensibilização, afetividade, esclarecimentos ou prestações de serviço.

Os públicos-alvo escolhidos para as AAE no curso de Direito representam grupos sociais diversos, desde alunos em idade de formação até pessoas em situação de vulnerabilidade, perpassando grande parte dos setores sociais componentes da comunidade.

O foco nos Direitos Humanos permite que todos os alunos se assenhorem do conhecimento e transmitam à comunidade com propriedade. Logo, se a Educação transforma vidas (FREIRE, 2020), a diversidade social é campo fértil para disseminar o conhecimento específico apreendido na IES, sendo sua contrapartida para com os municípios que enviam seus alunos para o ensino superior, numa interação constante.

São públicos-alvo das AAE no curso de Direito no setor público: repartições públicas, autarquias, fundações e serviços públicos em geral. No mercado: empresas, instituições privadas e sociedades. Na sociedade civil organizada: instituições religiosas, políticas, agremiações, associações profissionais, clubes cívicos, associações civis, colegiados, coletivos, etc. No terceiro setor: organizações não-governamentais, fundações, entidades beneficentes, fundos comunitários e entidades sem fins lucrativos. Nas instituições de ensino em qualquer nível: escolas de ensino infantil, fundamental, médio ou técnico, públicas ou privadas. Nos grupos sociais diversos: crianças, adolescentes, população LGBTQI+, mulheres, pessoas com deficiência, idosos, drogaditos ou alcoólicos, institucionalizados em abrigos, creches, asilos, hospitais, casas de repouso, clínicas de recuperação, instituições de longa permanência ou nãoinstitucionalizados em famílias, coletivos, grupamentos e pessoas em situação: de rua, de risco, de miséria ou de vulnerabilidade social.

Dada a indissociabilidade entre ensino, pesquisa e extensão, os temas tratados nas AAE têm aderência com o que se ensina, o que se pesquisa e o que a sociedade deseja. Dessa forma,

Revista Extensão \& Cidadania, v. 9, n. 15, p. 131-143 jan./jun. 2021. 
a participação atuante da comunidade na escolha das temáticas e identificação das demandas é imprescindível para que a atividade extensionista seja eficaz. Essa forma de atividade contribui para articular o ensino, pesquisa e extensão, gerando interações entre universidade e sociedade, para um aprofundamento democrático interno e externo à IES (SANTOS; ALMEIDA FILHO, 2009).

Assim, a troca de conhecimentos, a participação e o contato com as questões presentes no contexto social fora do ambiente acadêmico universitário contribuem, de forma efetiva, na formação dos alunos da IES como profissionais e cidadãos críticos, éticos e responsáveis e ajuda a transformar a realidade dos municípios em seu entorno.

A partir da escolha das modalidades e escolha do público-alvo, o objetivo geral das AAE no curso de Direito é promover a interação entre a IES e a comunidade dos municípios atendidos por ela. Para atingir este objetivo é preciso despertar o senso crítico no público-alvo dos municípios atendidos pela IES; disseminar o conhecimento na área dos Direitos Humanos; integrar o conhecimento apreendido em sala de aula com atividades de campo; formar parcerias entre a IES e grupos sociais; e divulgar as atividades de ensino, pesquisa e extensão da IES.

No tocante às AAE, os alunos desenvolvem as seguintes habilidades e competências, previstas no Projeto Pedagógico do Curso de Direito (UNIPAC, 2015): Leitura, compreensão e elaboração de textos e documentos; correta utilização da linguagem, com clareza, precisão e propriedade; fluência verbal e escrita, com riqueza de vocabulário; julgamento e tomada de decisões; habilidade crítica e reflexiva das relações sociais; capacitação para atuar como operador do Direito com interdisciplinaridade; visão criativa; responsabilidade social e profissional; e consciência dos problemas de seu tempo e de seu espaço.

Além disso, a todo momento é capaz de aplicar, na prática, os princípios da ética, justiça, da democracia, da cidadania, da dignidade da pessoa humana, da alteridade, da diversidade e pluralismo cultural, além dos princípios da solidariedade e dos direitos humanos.

\section{Metodologia}

Tendo em vista a produção de conhecimento, as AAE sustentam-se em metodologias participativas, no formato pesquisa-ação, que prioriza a participação dos atores sociais e o diálogo e que, para Boaventura de Sousa Santos e Naomar de Almeida Filho (2009), é uma área de legitimação da universidade, para além da extensão, envolvendo pesquisa e formação.

Revista Extensão \& Cidadania, v. 9, n. 15, p. 131-143 jan./jun. 2021. 
As atividades extensionistas foram desenvolvidas individualmente ou em grupo, neste caso, um representante escolhido entre eles intermediava o diálogo com o Professor Orientador e o Público-alvo. Assim, os alunos da IES tiveram encontros com as lideranças de cada grupo social, representantes, responsáveis ou diretores para apresentação e sensibilização das atividades extensionistas, munidos de cartas de apresentação assinadas pelo Professor Orientador. Dessa reunião foram levantadas as demandas e escolhida a atividade extensionista mais adequada, designando-se, conforme o caso, data e hora para execução. Neste interim, houve reuniões entre os alunos para planejamento e desenvolvimento da atividade extensionista, conforme sua finalidade, sob a supervisão do Professor Orientador para orientação, registro e acompanhamento.

As AAE no curso de Direito, como em qualquer atividade acadêmica, são avaliadas em processo contínuo, buscando seu aperfeiçoamento, de forma interna e externa. A avaliação interna é feita quando da entrega de Relatório à Comissão Própria de Avaliação (CPA), ao Núcleo Docente Estruturante (NDE), e ao Colegiado do Curso de Direito da IES. A avaliação externa foi feita durante a execução da atividade extensionista, em que o público-alvo pôde avaliar o desempenho dos alunos e da atividade por meio de formulário de avaliação de evento, cujo resultado é analisado para adequações nos planejamentos futuros. Além disso, a Coordenação do Curso e o Professor Orientador avaliam as Atividades desenvolvidas.

Após a execução das AAE, os alunos da IES confeccionaram Relatório Final das atividades executadas, com registro fotográfico e considerações sobre as atividades desenvolvidas. Foram recebidos no primeiro semestre o total de vinte Relatórios no período de oferta, entre 02 de março e 15 de julho de 2020. No segundo semestre, foram recebidos dezessete Relatórios no período de oferta, entre 10 de agosto e 04 de dezembro de 2020 . Ao todo, foram recebidos trinta e sete Relatórios (JACOB; SCARABELLI, 2020). Levando em conta a diminuição dos grupos a partir do segundo semestre, pode-se inferir a preferência pelas ações em grupo, o que pode sugerir o despertar da capacidade de atuação associada e coletiva no processo comunicativo, que é uma competência esperada para o egresso do curso de bacharelado em Direito.

Após o recebimento dos Relatórios Finais foram confeccionados ao todo trezentos e vinte e quatro relatórios individuais, conforme prevê o artigo 13 do Regulamento para Curricularização das Atividades de Extensão dos Cursos de Graduação da Faculdade Presidente Antônio Carlos de Aimorés, para fins de registo. Em cada relatório foram atestadas as

Revista Extensão \& Cidadania, v. 9, n. 15, p. 131-143 jan./jun. 2021. 
competências e habilidades desenvolvidas pelos alunos durante as atividades extensionistas realizadas e a carga horária total da atividade (JACOB, SCARABELLI, 2020).

\section{Dos resultados encontrados durante a implantação}

Os resultados das AAE levam em consideração os seguintes parâmetros: custos, participação dos alunos; nível de exequibilidade; visibilidade para a Faculdade; modalidades e atividades extensionistas desenvolvidas; impacto; e possibilidade de geração de produtos.

Quanto aos custos, em que pese estarem previstos no Formulário de submissão do Projeto, durante o ano de 2020 não houve nenhum custo extraordinário, ou seja, além dos custos remuneratórios dos recursos humanos, das AAE no Curso de Direito. Conforme previsto, pela natureza interinstitucional que a Extensão tem, foi possível manter as atividades sem custo extraordinário em razão das parcerias e convênios com outras instituições.

Quanto à participação dos alunos, em 2020, apenas 5 das 37 atividades extensionistas foram realizadas individualmente. Em comum, esses cinco alunos dividem a discência com atividade docente, então já estão acostumados ao cotidiano em sala de aula e ao ato de ensinar.

Todas as outras atividades extensionistas foram desenvolvidas em grupo. A julgar pelo perfil variado dos alunos do curso de Direito pode-se avaliar de maneira positiva que a maioria das atividades tenha sido coletiva, em total consonância com o caráter dos Direitos Humanos e, como já dito, pode sugerir o despertar da capacidade de atuação associada e coletiva no processo comunicativo, que é uma competência esperada para o egresso do curso de bacharelado em Direito.

Em 2020, não foi possível a integração com outros alunos de outros cursos, contudo, foi percebida e incentivada a interação entre alunos dos períodos em oferta nos semestres $\left(1^{\circ}\right.$ ao $10^{\circ}$ ), o que, inevitavelmente, possibilitou a integração de conteúdo e maior sociabilidade entre os alunos.

No primeiro semestre de 2020, a participação chegou aos 98,17\%, pois à época eram 163 alunos matriculados. No segundo semestre, o número de alunos se rearranjou em razão da entrada de novos alunos e a evasão de alunos durante a pandemia, sendo 169 matriculados e a participação chegou a 96,45\%. Mesmo com alguma queda, a participação dos alunos foi próxima de 100\% (JACOB; SCARABELLI, 2020). Destaca-se que ainda com expectativa de baixa participação em virtude da pandemia por Covid-19 o resultado foi bastante positivo.

Revista Extensão \& Cidadania, v. 9, n. 15, p. 131-143 jan./jun. 2021. 
Quanto ao nível de exequibilidade das atividades extensionistas, as modalidades escolhidas pelos alunos foram totalmente capazes de serem desenvolvidas em razão do tempo disponível e a disponibilidade dos participantes. Pode-se dizer que as atividades foram viáveis e coerentes com a infraestrutura disponível aos alunos. De se destacar que, como já dito, não houve nenhum custo adicional ou extraordinário nas atividades extensionistas, prova que não houve oneração dos alunos ou da Instituição. Assim, houve facilidade para a execução, considerando a proximidade do local a ser executada a atividade extensionista com o local de moradia dos alunos, o que, sem dúvida, contribuiu como fator positivo para o interesse e participação.

Quanto à visibilidade para a Faculdade, na proposta de submissão havia possibilidade de divulgação da IES na forma de mídias impressas, inviabilizada pela ocorrência da quarentena em razão da pandemia por Covid-19, tendo em vista que a estratégia mercadológica visava a atividade extensionista Cidadania nas Escolas, onde o público-alvo se confunde com possíveis futuros alunos dos cursos ofertados pela Faculdade.

No entanto, não se perdeu a oportunidade de dar visibilidade à IES, tendo em vista que a emissão das cartas de apresentação foi feita em papel timbrado e os discentes apresentaramse como alunos da Instituição. Dessa forma a visibilidade foi positiva, o que poderá ter algum impacto na procura pelos cursos nos próximos anos, embora, não tenha sido o foco das Atividades Acadêmicas de Extensão.

Quanto às modalidades e atividades extensionistas desenvolvidas, verifica-se que os alunos apresentaram predileção pela modalidade Prestação de serviço em detrimento das demais (Programa, Projeto, Cursos, Oficinas e Eventos), embora, à exceção da modalidade Programa, todas as outras foram desenvolvidas ao longo do ano de 2020.

Quanto à atividade extensionista realizada, na proposta a prospecção era que a maioria das ações fossem na modalidade de Cursos e Eventos, impulsionados pela atividade extensionista Cidadania nas Escolas, que foi a primeira atividade divulgada entre os alunos, contudo, o resultado surpreendeu, porque a grande maioria das atividades foi desenvolvida como Solidariedade em Ações. Tal escolha pode ser explicada pela ocorrência da quarentena em razão da pandemia por Covid-19. De se ressaltar que a grande maioria das prestações de serviço foram materializadas por campanhas de arrecadação de alimentos, agasalhos e produtos de higiene e limpeza, devido ao cenário de crise econômica que a região está inserida.

Assim, vê-se como positivo o resultado, pois demonstrou o interesse do corpo discente em transformar o mundo em sua volta, "consciente dos problemas de seu tempo e espaço"

Revista Extensão \& Cidadania, v. 9, n. 15, p. 131-143 jan./jun. 2021. 
(UNIPAC, 2015), que é uma das competências previstas no Projeto Pedagógico do Curso de Direito.

Quanto ao impacto das AAE, a extensão difunde, socializa e democratiza o conhecimento com a comunidade, mas pode aprender com ela, pois se trata de formação complementar dos alunos, tal e qual o Estágio e as Atividades Complementares, especialmente pela aplicação prática. Assim, o tripé indissociável ensino, pesquisa e extensão se mantém de forma complementar e interdependente, pois no mesmo passo que o aluno adquire novos conhecimentos os difunde para além da sala de aula, socializando os saberes e tendo novas experiências de forma sistêmica.

As AAE tiveram impacto positivo, de forma geral, os alunos conseguiram comunicarse com suas realidades locais de forma criativa e certamente contribuiu em muito para a sua formação crítica e cidadã, pois muitos relatos dos alunos explicitam que a oportunidade foi, para alguns, uma quebra de paradigma pois encararam realidades muito diferentes de suas vivências.

Ousa-se dizer que, se não foram capazes de alterar a percepção dos alunos sobre o próximo, permitiram um questionamento de sua própria realidade, o que é sempre positivo para o processo de formação superior.

Durante as atividades extensionistas no primeiro e segundo semestres foram envolvidos três municípios do Espírito Santo (Baixo Guandu, Colatina e Itarana) e seis em Minas Gerais (Aimorés, Cuparaque, Itueta, Pocrane, Resplendor e Santa Rita do Ituêto). Nessas localidades, as instituições contempladas pelas atividades extensionistas foram as seguintes: $\mathrm{Na}$ atividade Cidadania nas Escolas: Centro Educacional Crescer em Aimorés-MG; Centro Educacional Municipal de Educação Infantil Maria Aparecida Sampaio Borba em Quatituba, Itueta-MG; Centro Estadual de Ensino Médio em Tempo Integral em Baixo Guandu-ES; Escola Municipal de Educação Infantil e Ensino Fundamental Professora Léa Holz em Baixo Guandu-ES; e Escola Municipal de Educação Infantil Pequenos Brilhantes em Aimorés-MG. Na atividade Cidadania em Ações: Asilo São Vicente de Paulo em Pocrane-MG; Associação de Amparo ao Menor Aimoreense - AAMAR em Aimorés-MG; Associação de Pais e Amigos dos Excepcionais em Resplendor-MG; Corpore Academia em Aimorés-MG; Faculdade Presidente Antônio Carlos de Aimorés-MG; Público em geral pelo Instagram ${ }^{\circledR}$; e Secretaria de Saúde de Cuparaque-MG. Na atividade Solidariedade em Ações: Asilo Jesus Nazareno em Aimorés-MG; Asilo São Vicente de Paulo em Pocrane-MG; Asilo Recanto da Dignidade em Resplendor-MG; Associação Melhores Amigos dos Animais - AMAA em Baixo Guandu-ES; Associação

Revista Extensão \& Cidadania, v. 9, n. 15, p. 131-143 jan./jun. 2021. 
Focinhos Carentes em Aimorés-MG; Associação de Amparo ao Menor Aimoreense - AAMAR em Aimorés-MG; Associação de Pais e Amigos dos Excepcionais em Aimorés-MG; Casa de Triagem Encontro com a Vida em Aimorés-MG; Hospital São Jose e São Camilo em AimorésMG; Secretaria de Assistência Social de Baixo Guandu-ES; $6^{\circ}$ Pelotão de Bombeiro Militar em Resplendor-MG; Pessoas em situação de rua em Baixo Guandu-ES; Hemocentro Regional de Colatina-ES (JACOB; SCARABELLI, 2020).

A julgar pelas avaliações das atividades extensionistas fornecidas pelas entidades atendidas, pode-se entender que o impacto foi positivo, pois ressaltaram a preparação dos alunos, estando bem informados sobre o tema proposto, auxiliando o público-alvo a obter novos aprendizados ou conhecimento, inclusive com possibilidade de recomendação para outras pessoas. Pode-se dizer que os alunos acertaram na identificação das demandas da comunidade atendida, em razão da participação dos representantes e diretores na discussão das atividades. Isso teve peso na boa recepção das AAE pela comunidade e foi relevante no aspecto social, ambiental, educacional e econômico dos problemas encontrados.

Houve também impacto positivo na interação com os setores sociais envolvidos e com órgãos sociais que não foram cogitados na Proposta, como a participação das Secretarias de Saúde e de Assistência Social de alguns Municípios e os Bombeiros e a Polícia Militar de Minas Gerais. Foram surpresas positivas do alcance e integração que a Extensão propiciou, podendo se consolidar parcerias entre a IES e essas instituições.

Quanto à possibilidade de geração de produtos, as AAE têm potencial para gerar vários produtos acadêmicos em articulação com o ensino e a pesquisa, dentre outras: Cursos de extensão universitária; Formação continuada em áreas diversas; Eventos técnico-científicos diversos; Eventos artísticos e culturais; Prestação de assistência jurídica além das desenvolvidas pelo Núcleo de Prática Jurídica; Comunicações científicas; e publicações científicas.

Pelo fato de ser o primeiro ano da oferta, enquanto ainda não se torna obrigatória a extensão, os resultados permanecem como metas para 2021, como publicações de artigos científicos em revistas especializadas; transformação de projetos desenvolvidos em programas contínuos; formação de parcerias de propostas viáveis, que ainda dependem da normalização das relações sociais (fim da pandemia); ofertas de minicursos de extensão; criação de grupos de pesquisa; desenvolvimento de projeto de ensino no curso de Direito; eventos de engajamento comunitário, manutenção do curso extraordinário zero, dentre outras. As metas levam em consideração os resultados obtidos no ano de 2020 e as experiências positivas e que constituíram desafios para as ações extensionistas.

Revista Extensão \& Cidadania, v. 9, n. 15, p. 131-143 jan./jun. 2021. 


\section{Considerações finais}

À guisa de conclusão deste relato de experiência, resta pontuar que diante das dificuldades apresentadas: a suspensão das aulas presenciais e todas as incertezas do cenário da educação superior presencial brasileira e a consequente apatia dos alunos pela nova modalidade de ensino e as expectativas negativas que toda mudança traz, não houve debandada dos alunos, que encamparam a ideia e permitiram resultados positivos. A apatia pode até ter ficado com a modalidade de ensino, mas as AAE não enfrentaram resistência neste cenário.

Ainda que, no decorrer do desenvolvimento tenhamos sido surpreendidos pela quarentena em razão da pandemia por Covid-19, as atividades extensionistas permaneceram alinhadas à área temática e linha programática. Pelas avaliações devolvidas das entidades beneficiadas, o contentamento e satisfação demonstrados pela comunidade permitiu concluir que os Direitos Humanos foram destacados nas atividades desenvolvidas, honrando o compromisso com o tema da Extensão da IES.

Os resultados foram positivos, mas o mais relevante é a importância que a Extensão tem na formação do aluno que, neste caso, é a formação integral, permitida pela efetiva interação com a sociedade, transformando a sua formação profissional futura não apenas acadêmica, técnica e científica, mas também humanística, axiológica e crítica.

\section{Referências}

ALVES, Luiz Roberto. Estender-se comunicando: o caminho para a universidade que forma sujeitos (uma leitura freiriana). In: CÂNDIDO, João G.; SILVA, Luciane D. (org.). Extensão universitária: conceitos, propostas e provocações. São Bernardo do Campo: Universidade Metodista de São Paulo, 2014.

BRASIL. Lei no 9.394 de 20 de dezembro de 1996. Brasília-DF: Senado, 1996.

FREIRE, Paulo. Educação e mudança. 43. ed. Rio de Janeiro: Paz \&Terra, 2020.

JACOB, Alexandre; SCARABELLI, Paloma Silveira Braga e Souza. Relatório final do projeto atividades acadêmicas de extensão no Direito. Aimorés: Unipac, 2020.

BRASIL. Ministério da Educação. Conselho Nacional de Educação. Câmara de Educação Superior. Resolução nº . 7, de 18 de dezembro de 2018. Brasília-DF: MEC, 2018.

Revista Extensão \& Cidadania, v. 9, n. 15, p. 131-143 jan./jun. 2021. 
PIOVESAN, Flávia. Democracia, direitos humanos e globalização econômica: desafios e perspectivas para a construção da cidadania no Brasil. 2016. Disponível em:

https://bit.ly/3jqbFGn. Acesso em: 20 jul. 2020.

SANTOS, Boaventura de Sousa; ALMEIDA FILHO, Naomar. A universidade no século XXI: para uma universidade nova. Coimbra: Almedina, 2009.

THIOLLENT, Michel Jean Marie; COLETTE, Maria Madalena. Pesquisa-ação, universidade e sociedade. Revista Mbote, Salvador, v. 1, n. 1, 2020.

UNIPAC. Faculdade Presidente Antônio Carlos de Aimorés. Projeto Pedagógico do curso de Direito. Aimorés: Unipac, 2015.

UNIPAC. Faculdade Presidente Antônio Carlos de Aimorés. Regulamento para curricularização das atividades de extensão dos cursos de graduação da Faculdade Presidente Antônio Carlos de Aimorés. Aimorés: Unipac, 2020.

Recebido: 08.05.2021

Aceito: 19.06.2021

Revista Extensão \& Cidadania, v. 9, n. 15, p. 131-143 jan./jun. 2021. 